Revista de la Escuela de Ciencias de la Educación, año 14, nRo. 13, vol. 2, julio a diciembre de 2018. Páginas 33-51. ISSN 1851-6297 (DESDE DICIEMBRE DE 2006 A DICIEMBRE DE 2017). ISSN 2362-3349 (EN LINEA). ¿ELEGIR POR VOCACIÓN O ELEGIR LA VOCACIÓN? EL DISCURSO VOCACIONAL EN ESTUDIANTES DE PROFESORADO Y DOCENTES NOVELES DE NIVEL PRIMARIO. Gustavo Mórtola y Maria Mercedes Lavalletto.

\title{
¿ELEGIR POR VOCACIÓN O ELEGIR LA VOCACIÓN? EL DISCURSO VOCACIONAL EN ESTUDIANTES DE PROFESORADO Y DOCENTES NOVELES DE NIVEL PRIMARIO
}

\author{
Gustavo Mórtola* \\ ENS N³ Bernardino Rivadavia / UNAJ, Argentina \\ formaciondocente.unaj@gmail.com \\ María Mercedes Lavalletto* \\ ENS N ${ }^{\circ} 3$ Bernardino Rivadavia / UBA, Argentina \\ mercedeslavalletto2000@gmail.com
}

Recibido: 24/09/2017 Aceptado: 17/11/2017

\section{Resumen}

En el presente artículo abordaremos algunas características de lo que denominamos como "discurso vocacional" en estudiantes de magisterio y docentes noveles de nivel primario de la ciudad de Buenos Aires. Nos focalizaremos en los significados que asume el significante vocación en el momento vital en que los individuos deciden ingresar al profesorado. Asumimos que el término vocación adquiere una particular relevancia y operatividad social cuando los individuos toman decisiones respecto de los estudios profesionales de nivel superior por los cuales optan. Si bien consideramos que la vocación se "tiene" o "no se tiene" - tomando para ello las formas típicas en que el discurso voca-

* Es Profesor para la Enseñanza Primaria. Magister en Política y Administración de la Educación (UNTREF). Lic. en Ciencias de la Educación (UBA). Docente de la asignatura "Trabajo docente" (ENS N 3 "Bernardino Rivadavia" - CABA) y del "Taller de formación docente" (Licenciatura de Kinesiología y Fisiatría - UNAJ).

* Es Profesora y Licenciada en Ciencias de la Educación (UBA). Especialista en Tecnología Educativa (UBA), Especialista en Ciencias Sociales con mención en Curriculum y Prácticas Escolares en contexto (FLACSO) y maestranda en Formación Docente (UNI$P E)$. Docente de la asignatura "Didáctica I" y "Didáctica II" (ENS N 3 "Bernardino Rivadavia" - CABA). 
Revista de la Escuela de Ciencias de la Educación, año 14, nRo. 13, vol. 2, julio a diciembre de 2018. PÁginas 33-51. ISSN 1851-6297 (DESDE DICIEMBRE DE 2006 A DICIEMBRE DE 2017). ISSN 2362-3349 (EN LINEA). ¿ELEGIR POR VOCACIÓN O ELEGIR LA VOCACIÓN? EL DISCURSO VOCACIONAL EN ESTUDIANTES DE PROFESORADO Y DOCENTES NOVELES DE NIVEL PRIMARIO. Gustavo Mórtola y Maria Mercedes Lavalletto.

cional se enuncia - nos alejamos de cualquier postura esencialista ("soy maestra de alma") o innatista ("nací para ser maestro"). Nos interesa analizar cómo el discurso vocacional se imbrica con la particular división del trabajo contemporáneo y los procesos de individuación que caracterizan nuestro presente.

Palabras clave: Vocación - Formación - Socialización - Identidades - Discurso.

\begin{abstract}
In this article we will address some of the characteristics of what we call "vocational discourse" in primary level teachers and teaching students of the city of Buenos Aires. We will focus on the meanings of the term vocation in the vital moment when individuals decide to study teaching education.We assume that the term vocation acquires a particular relevance and social operability when individuals make decisions about the professional studies they opt for. While we believe that the vocation is "has" or "does not have" - taking for it the typical forms in which the vocational discourse is enunciated - we move away from any essentialist posture ("I am a soul teacher") or innate ("I was born to be a teacher").We are interested in analyzing how vocational discourse is related to the particular division of contemporary work and the processes of individuation that characterize our present.
\end{abstract}

Keywords: Vocation - Teacher education - Socialization - Identities Discourse.

\title{
Introducción
}

No es extraño leer en un diario o escuchar en la radio que un equipo de fútbol tiene "una importante vocación ofensiva" o que "un partido político tiene escasa vocación transformadora". En tales expresiones la palabra vocación aparece asociada a las características que asume el juego de un equipo deportivo o a las políticas que lleva adelante un partido político. Además, esta vocación tiene un monto determinado pues puede ser "importante" o "escasa". Este uso corriente de la palabra vocación expresa que este término participa del vocabulario que circula usualmente en nuestro tiempo presente y no solo en los medios de comunicación.

Sin embargo, la vocación no cuenta con buena prensa en algunos espacios sociales. En ciertos ámbitos académicos y gremiales del campo pedagógico no es una palabra que se enuncie con simpatía. O, directamente, sorprende que los docentes la sigan utilizando. En el muy recomendable libro "Maneras de querer" la pedagoga argentina Ana Abramowski expresa cierto asombro ante la aparición espontánea del término "vocación" en el discurso de los docentes primarios que había entrevistado para una investigación que 
Revista de la Escuela de Ciencias de la Educación, año 14, nRo. 13, vol. 2, julio a diciembre de 2018. Páginas 33-51. ISSN 1851-6297 (DESDE DICIEMBRE DE 2006 A DICIEMBRE DE 2017). ISSN 2362-3349 (EN LINEA). ¿ELEGIR POR VOCACIÓN O ELEGIR LA VOCACIÓN? EL DISCURSO VOCACIONAL EN ESTUDIANTES DE PROFESORADO Y DOCENTES NOVELES DE NIVEL PRIMARIO. Gustavo Mórtola y María Mercedes Lavalletto.

tenía como objeto a los afectos magisteriales. La pedagoga expone sus supuestos al afirmar que "dentro de los testimonios recogidos encontramos referencias espontáneas a este término que creíamos ya caduco, sepultado ante las demandas de reconocimiento de los docentes como "trabajadores de la educación" (Abramowski, 2010, p.85). No solo Abramowski demuestra sorpresa por los maestros primarios hablando de vocación en tanto que pedagogos de otras latitudes manifiestan el mismo desconcierto. Elia Estola (2003), una destacada pedagoga finlandesa que ha profundizado en torno a temas vocacionales en docentes de nivel primario, expresaba también desconcierto ante el uso del término vocación entre los maestros fineses. En tal sentido manifestaba que su interés por la vocación se originó por la "asombrosa observación de que los maestros hablaban de la vocación en forma significativa. Incluso los estudiantes de magisterio usaban esta palabra, a la cual considerábamos anticuada y religiosa: "necesitas algún tipo de vocación", muchos de ellos nos decían en clase" (Estola, 2003, p.38).

A partir de estas dos citas es posible afirmar que tanto en Argentina como en Finlandia la vocación docente continúa vigente. Ahora, ¿qué es la vocación? Y profundizando en el trabajo de enseñar: ¿Qué es la vocación docente? En el presente artículo abordaremos algunos aspectos de la vocación tal como la entienden ingresantes al magisterio, residentes y docentes de nivel primario con menos de dos años de experiencia profesional. Este escrito es el producto de una investigación realizada con estudiantes de profesorados de la ciudad de Buenos Aires y maestras y maestros en ejercicio de escuelas públicas de esa jurisdicción. Asumimos una metodología de investigación de tipo cualitativa y entrevistamos en profundidad a siete estudiantes ingresantes, a siete en el momento de hacer la residencia y a siete docentes con menos de dos años de experiencia profesional. Guiaron nuestra indagación los siguientes interrogantes: ¿Qué significados enuncian los estudiantes de magisterio y los docentes recientemente recibidos cuando hablan de la vocación en general y de la suya en particular? ¿Qué característica tiene este tipo discursivo? ¿Cómo se apropian del discurso vocacional los individuos que eligen la enseñanza primaria como campo profesional?

Para finalizar esta introducción vale la pena delimitar algunos aspectos de lo que entendemos por vocación. Desde nuestra perspectiva teórica la "vocación" es una palabra. Pero no es cualquier palabra por lo que recurriendo a cierto trillado fraseo sociológico sostenemos que la "vocación es más que una palabra". ¿Qué es la vocación entonces? Sostenemos que es un discurso social que, tal como sostiene el canadiense Marc Angenot (2010), comprende todo lo que se dice, escribe, imprime, habla públicamente o se representa en un estado particular de sociedad. Si un discurso tiene potencia social se manifiesta en torno a lo que se puede decir y en lo que es indecible, en las normas que rigen lo que decimos, en las jerarquías de los que hablan, en los 
Revista de la Escuela de Ciencias de la Educación, año 14, nRo. 13, vol. 2, julio a diciembre de 2018. PÁginas 33-51. ISSN 1851-6297 (DESDE DICIEMBRE DE 2006 A DICIEMBRE DE 2017). ISSN 2362-3349 (EN LINEA). ¿ELEGIR POR VOCACIÓN O ELEGIR LA VOCACIÓN? EL DISCURSO VOCACIONAL EN ESTUDIANTES DE PROFESORADO Y DOCENTES NOVELES DE NIVEL PRIMARIO. Gustavo Mórtola y Maria Mercedes Lavalletto.

grupos que se conforman alrededor de ciertas a formas del habla y los que son excluidos.

Nos centraremos en el presente artículo en un particular momento vital que es el ingreso al profesorado. Asumimos que en el tránsito hacia los estudios superiores la palabra vocación adquiere relevancia y operatividad social. ¿Qué significa el término vocación para unos individuos que ingresan a un profesorado para estudiar el Profesorado para Enseñanza Primaria? Intentaremos a continuación dar respuesta a este interrogante.

\section{Algunos antecedentes}

Diversos trabajos de carácter sociológico iluminan el análisis del discurso vocacional. Weber (2001 y 1999) puede ser considerado un clásico con sus estudios en torno a la división del trabajo y el sentido vocacional en campos como la política o la religión. También desde la sociología, constituyen un antecedente a considerar los trabajos de Tenti Fanfani (Tenti Fanfani 2010; Tenti Fanfani y Grimson, 2014) en los que analiza la condición docente y el carácter de oficio que tiene este campo laboral. Este autor sugiere que el oficio docente se caracterizó históricamente por una mezcla no siempre equilibrada entre profesionalismo y vocación. También fundamenta en base a estudios de diversa índole metodológica que el componente vocacional del oficio se niega a desaparecer, pero se redefine a partir de las mutaciones sociales contemporáneas. Un sociólogo francés que aporta importantes definiciones en torno a las conocidas como profesiones del cuidado (docencia, enfermería y trabajo social) es Francois Dubet (2004). Dubet sostiene que el ideal vocacional ha pasado del altar de lo sagrado a una fisonomía más laica, menos heroica, "más protestante". Agrega que la vocación ha mutado desde idearios vinculados con la adhesión y el sacrificio a valores superiores hacia ideologías laborales que propugnan la realización del yo en el trabajo/empleo.

Desde perspectivas que abonan en la historiografía es relevante destacar el período que se extiende aproximadamente desde mediados del siglo XIX al primer cuarto del siglo XX. Al respecto, diversos trabajos de tipo históricos analizan el nacimiento del normalismo, la conformación de un subsistema formador de docentes y la titulación de, al decir de Alliaud (1993), un "ejército de maestros patrioteros" con enorme sentido vocacional. Birgin (1999) y Lionetti (2004) describen este período histórico colocando a la vocación conjuntamente con la abnegación, el sentido pastoral y sacerdotal, las formas ascéticas y sacrificiales como dominantes en la discursividad hegemónica de la época. En estos estudios se puede apreciar cómo tanto en los centros de poder vinculados al estado educador como en las enormes masas de mujeres y hombres que se formaron como maestras y maestros, la vocación adquirió fuerza hegemónica.

Lectores atentos de Dubet, los argentinos Alliaud y Antelo (2009) analizan el trabajo de enseñar desde perspectivas pedagógicas. Ambos señalan el lu- 
Revista de la Escuela de Ciencias de la Educación, año 14, nRo. 13, vol. 2, julio a diciembre de 2018. Páginas 33-51. ISSN 1851-6297 (DESDE DICIEMBRE DE 2006 A DICIEMBRE DE 2017). ISSN 2362-3349 (EN LINEA). ¿ELEGIR POR VOCACIÓN O ELEGIR LA VOCACIÓN? EL DISCURSO VOCACIONAL EN ESTUDIANTES DE PROFESORADO Y DOCENTES NOVELES DE NIVEL PRIMARIO. Gustavo Mórtola y María Mercedes Lavalletto.

gar vocacional que asume el ejercicio de la docencia, particularmente en el nivel inicial y primario. Antelo sostiene que hoy los maestros asumen perspectivas más narcisistas que ponen en tensión anteriores mandatos vocacionales relacionados con el deber. Para este autor, el deber, el sacrificio, lo sagrado y lo apostólico del discurso vocacional aparecen tensionados por un desempeño laboral más asociado al placer, el goce y a una realización personal de tipo narcisista.

\section{Vocación e ingreso a los estudios de magisterio}

Estudiar para el desempeño de una profesión parece ser en la actualidad el hecho más natural del mundo. Esta naturalidad se acrecienta cuando múltiples campos laborales exigen titulaciones para su ejercicio. En tiempo presente enormes masas de individuos estudian durante varios años en el nivel superior para ocupar las más diversas profesiones. Pero esto no siempre ha sido así y aun hoy solo unas minorías poblacionales acceden a titulaciones profesionales.

¿Qué discursos enuncian los individuos para explicar la decisión de realizar estudios de tipo profesional? El proceso de construcción de un gusto o inclinación por una determinada profesión se denomina circunscripción profesional (Gottfredson, 2002). Muchas personas identifican en algún momento de sus trayectorias vitales la ocupación que más prefieren de acuerdo a la evaluación de compatibilidad que realizan entre varias profesiones y la imagen de sí mismos que portan. Las preferencias se expresan en las formas en que la masculinidad y la femineidad son visibilizadas por uno mismo y por los otros, la forma en que una determinada profesión se vincula con cierta posición social entre los grupos de referencia y la garantía de que el compromiso que el trabajo requiere podrá ser asumido por la propia personalidad. Narrar para sí mismo y para otros este proceso de circunscripción profesional conlleva la existencia de un discurso social específico.

Las entrevistas realizadas en la presente investigación adquirieron en muchos pasajes tonos biográficos y, en tales circunstancias, los individuos como narradores brindaron razones en su intento de explicar un determinado desarrollo de acontecimientos de sus vidas. En tal sentido los individuos al narrar, explican (Verd, 2006). Además, podemos considerar al ingreso a estudios profesionales como un incidente crítico de la vida de una persona en tanto está tomando una decisión relevante en torno de su futuro (Measor, 1985). Estos incidentes constituyen balizamientos en los que la trayectoria vital cambia y los relatos no se entienden sin explicitar las vinculaciones causales entre un suceso clave de la vida y su posterior desarrollo.

¿Qué razones, motivos y razones los estudiantes y docentes entrevistados enuncian para explicar su ingreso al profesorado? No nos detendremos en dar una respuesta a esta pregunta que hemos abordado en otros trabajos 
Revista de la Escuela de Ciencias de la Educación, año 14, nRo. 13, vol. 2, julio a diciembre de 2018. PÁginas 33-51. ISSN 1851-6297 (DESDE DICIEMBRE DE 2006 A DICIEMBRE DE 2017). ISSN 2362-3349 (EN LINEA). ¿ELEGIR POR VOCACIÓN O ELEGIR LA VOCACIÓN? EL DISCURSO VOCACIONAL EN ESTUDIANTES DE PROFESORADO Y DOCENTES NOVELES DE NIVEL PRIMARIO. Gustavo Mórtola y Maria Mercedes Lavalletto.

pero señalaremos que son explicaciones multicausales que mixturan diversas motivaciones (Mórtola y Lavalletto, 2016). Así manifiestan que ingresaron al profesorado porque les atrae enseñar, por amor o gusto por los niños, por aspiraciones de transformar la sociedad, porque en sus familias hay docentes, porque el profesorado les queda cerca, entre otras razones, causas y motivaciones.

Ninguno de los estudiantes ni de los docentes noveles entrevistados manifestó haber ingresado por "vocación" o por algo parecido a "un llamado" tal como la vocación ha sido representada históricamente (French, 2006). Desde nuestras hipótesis previas esperábamos encontrar algunos estudiantes o docentes en ejercicio que nos brindasen tales tipos de respuesta. Más cuando algunas investigaciones clásicas del campo de la formación docente que realizaron encuestas para indagar las motivaciones del ingreso al magisterio incorporaron en sus instrumentos la respuesta "por vocación" o "por un llamado interior" cuando interrogaban a sus encuestados en torno a las razones por las que habían ingresado a la docencia (Birgin y Pineau, 2006; Davini y Alliaud, 1995).

Sin embargo, la vocación apareció sin que la llamasen en las narrativas que enuncian los motivos, causas y razones de ingreso al profesorado. Un primer tópico que es interesante de ser analizado es que los términos "vocación" y "elección" aparecen estrechamente vinculados y cercanos en estas narrativas. Como si un término no pudiese ser enunciado sin recurrir al otro. $Y$ bien vale señalar que se les preguntó por qué habían ingresado al profesorado sin incluir en el interrogante ni la palabra "vocación" ni tampoco el verbo "elegir".

Es raro porque yo soy mucho más parecido a mi papá que a mi mamá pero al momento de elegir la vocación digamos me incliné más para el lado de mi mamá (Diego, 19 años, ingresante).

$Y$ yo quise elegir... esto es algo que lo hablé con Marta, una amiga, en el trabajo docente. La vocación mía era por un trabajo que yo pudiera competir con 35, 40 años, con un pibe de 20 recién recibido, de 24 años. Es una carrera, la docencia que, si tenés 40 o tenés 25 da lo mismo. Va el puntaje, no la edad (Leandro, 39 años, residente).

Elegí un poco ayudada por mi pareja que él también es docente, me decía, bueno, que es una carrera que le gustaría que yo haga porque venía de un cambio de carrera, de vocación, y tome por el sí y acá estoy intentando llevarla a cabo lo mejor posible (Florencia, 34, ingresante).

Como se podrá observar, ni Diego, ni Leandro ni Florencia asocian el término vocación con ningún valor esencialista, ni innatismos de ninguna clase ni tampoco llamados o epifanías laborales. La vocación es para ellos un término asociado a la elección de unos estudios que permiten acceder a una profesión como la enseñanza primaria. 
Revista de la Escuela de Ciencias de la Educación, año 14, nRo. 13, vol. 2, julio a diciembre de 2018. Páginas 33-51. ISSN 1851-6297 (DESDE DICIEMBRE DE 2006 A DICIEMBRE DE 2017). ISSN 2362-3349 (EN LINEA). ¿ELEGIR POR VOCACIÓN O ELEGIR LA VOCACIÓN? EL DISCURSO VOCACIONAL EN ESTUDIANTES DE PROFESORADO Y DOCENTES NOVELES DE NIVEL PRIMARIO. Gustavo Mórtola y María Mercedes Lavalletto.

Es destacable que si bien ninguno manifiesta haber elegido estudiar magisterio por vocación, hay otros - los compañeros - que sí pueden elegir el trabajo de enseñar en el nivel primario por motivos vocacionales. Pero bien vale interrogarse acerca de qué es esa vocación que los otros portan o es interpretada como causa de su elección del magisterio.

Hay de todo, yo creo que hay de todo. Hay gente que elige por vocación, porque siempre quiso ser eso y hay otro más en mi situación. Querrán cambiar los trabajos o una salida laboral (Malena, 34 años, residente).

Sé de algunos que han entrado porque se desencantaron de otras carreras, por el trabajo, por las condiciones laborales. Hay más acceso al trabajo que en otras carreras. Por vocación también, porque les gusta ser maestros. Otros hacen carreras universitarias y al recibirse antes hacen este trabajo y pueden terminar la carrera universitaria. En todos estos años he conocido muchos motivos (Luciana, 39 años, residente).

Si la profesión se elige no es de extrañar que el término vocación asuma un significado asociado con el gusto, la inclinación o el anhelo de convertirse en docente de nivel primario. Por otra parte, a un individuo pueden gustarle varios campos profesionales que necesiten de prolongados períodos de estudios formativos para su desempeño. Ese gusto o inclinación puede ser detectado por otros y puede denominarse como vocación. Martina enuncia un camino sinuoso entre el teatro y la docencia que se explicita como una vocación que fue incentivada por una docente del secundario.

Recuerdo a mi maestra del secundario, profesora de Literatura, que, bueno, con ella empecé un poco a descubrir la vocación del teatro, por un lado. Esto es lo que me gusta. Y también ella fue la que me empezó a incentivar con que siga una carrera docente porque me veía una aspiración, y ahí... como una imagen docente que estaba buena (Martina, 24 años, residente).

Son otros los que ponen en juego esta fuerte vinculación entre vocación y elección, aunque a veces puedan ser hasta términos contradictorios entre sí o que ven en ellos características que no pertenecen a la propia autoimagen.

Hay maestras que me dicen: "ah, lo tuyo es vocación, yo si estuviera en tu situación no vuelvo a elegir ser maestra". Y yo digo: "bueno, pero vos vivís otra situación. Yo fui criada así, trabajé con chicos en esta situación" (Mora, 26 años, residente).

Algunos me dijeron: Bueno, tenés que tener vocación para ser docente. Y no sé si es tan así. En base a lo que estuve viendo este primer mes no sé si es tanto de vocación. Es un poco más de perseverancia y algo de trato con los chicos pero no sé si tanto como vocación. Después de tener varias charlas respecto a esto una persona me dijo quizás tenés razón acerca de la vocación pero me parece que la vocación vos la tenés igual. Nos 
Revista de la Escuela de Ciencias de la Educación, año 14, nRo. 13, vol. 2, julio a diciembre de 2018. PÁginas 33-51. ISSN 1851-6297 (DESDE DICIEMBRE DE 2006 A DICIEMBRE DE 2017). ISSN 2362-3349 (EN LINEA). ¿ELEGIR POR VOCACIÓN O ELEGIR LA VOCACIÓN? EL DISCURSO VOCACIONAL EN ESTUDIANTES DE PROFESORADO Y DOCENTES NOVELES DE NIVEL PRIMARIO. Gustavo Mórtola y Maria Mercedes Lavalletto.

reímos y nada, quedó ahí (Néstor, 28 años, ingresante).

Son colegas o amigos como en los casos de Mora y Néstor los que ven en ellos vocación para ser docentes. Sin embargo, es interesante agregar que ninguno de los dos ven en sí mismos algo que pueda llamarse vocación. Un término que parece ser objeto de disputas, particularmente cuando otros lo utilizan para evaluar a individuos que han elegido un campo profesional por motivos que para ellos son otros. Por último, es destacable el uso de la palabra vocación que hace la joven ingresante Magalí: los test vocacionales.

Y bueno empecé a averiguar desde ese lado qué me podía llegar a gustar pero yo no tenía ni idea lo que era el diseño gráfico. Así que bueno fui a averiguar, a investigar y al principio bueno me interesó, me copó y me metí y no terminó siendo lo que esperé o no me terminó dando la imagen que yo me di, como que a la hora de proyectarme no me vi en un futuro haciendo eso. Y dije bueno por qué no remontarme a lo que siempre supe que quería hacer y empecé a hacer una búsqueda de cero, desde mis intereses, tests vocacionales, por Internet, todo eso, también pidiendo consejos a familiares y amigos y bueno acá estoy (Magalí, 18 años, ingresante).

La palabra vocación aquí aparece vinculada con una práctica social llevada adelante por profesionales que orientan la elección entre los múltiples campos profesionales existentes. Para ser más específicos los orientadores vocacionales guían a los individuos al momento de optar entre la diversidad de opciones para realizar estudios de nivel superior. Sergio Rascovan (2004), un psicólogo argentino dedicado a estas temáticas, menciona que el nacimiento de este campo especializado se puede rastrear en los trabajos de Frank Parsons en los Estados Unidos a comienzos del siglo pasado quien acuñó el término "choosing a vocation" (Trad: eligiendo una vocación). Vemos como el término "elegir" se imbrica con "vocación", aquí asociada al nacimiento de un cuerpo de profesionales que se ocupan de orientar un camino entre la diversidad de los estudios de tipo profesional a multitudes nacientes de individuos que podían optar. Es indudable que la orientación vocacional se ha convertido en un ámbito social de prácticas profesionales vinculadas con las formas en las que ciertos individuos definen qué estudios realizar. El uso de "ciertos" expresa que solo algunas minorías gozan de esta posibilidad. Minorías amplias en nuestro tiempo, pero minorías al fin y al cabo.

Así, la orientación vocacional puede ser entendida como "un "invento" de la modernidad para asistir a las personas que se preguntan por su hacer, presente y futuro" (Rascovan, 2004, p. 2). Este campo profesional de prácticas y discursos específicos expresa una esfera de especialistas que ayudan a las personas haciéndolos preguntarse acerca de su pasado y presente en pos de un devenir en algún campo profesional. Preguntas y respuesta que implican discursos sobre uno mismo y en torno a opciones de carreras de nivel superior que conlleva 
Revista de la Escuela de Ciencias de la Educación, año 14, nRo. 13, vol. 2, julio a diciembre de 2018. Páginas 33-51. ISSN 1851-6297 (DESDE DICIEMBRE DE 2006 A DICIEMBRE DE 2017). ISSN 2362-3349 (EN LINEA). ¿ELEGIR POR VOCACIÓN O ELEGIR LA VOCACIÓN? EL DISCURSO VOCACIONAL EN ESTUDIANTES DE PROFESORADO Y DOCENTES NOVELES DE NIVEL PRIMARIO. Gustavo Mórtola y María Mercedes Lavalletto.

estudiar durante varios años, obtener una titulación y trabajar durante un largo período de tiempo en un tipo de empleo al que se lo valora significativamente, se lo desea para uno mismo. Puede ser que ese lapso de tiempo se extienda por toda una vida laboral hasta la jubilación. Podemos concluir que la orientación vocacional es una esfera social de la que emergen discursos sobre la vocación, la elección, las profesiones y el mundo del trabajo/empleo.

Por lo tanto, que Magalí hable de test vocacionales expresa no solo que hay unos profesionales y unas prácticas especializadas en guiar la elección de una profesión. Nos habla de que la vocación como elección es un discurso social que representa unos fenómenos epocales de distribución de individuos en la compleja y fragmentada división del trabajo de nuestra época. $Y$ de individuos que tienen discursos sociales que preexisten a sus conciencias para explicar para sí y para otros la trayectoria laboral que van construyendo a lo largo de su vida. Por supuesto, en nuestro caso pone de manifiesto a individuos que han optado por un campo en particular: el profesorado para la enseñanza primaria.

\section{Subjetividades probadoras}

Hemos descripto cómo vocación y elección profesional están profundamente vinculadas en los discursos que enuncian los individuos entrevistados cuando explican las razones, motivos y causas por las que han ingresado al magisterio. Un núcleo de significación que parece manifestar que gran parte de los entrevistados "eligen la vocación". De esta manera el término vocación adquiere tonos laicos y profesionistas por lo que lejos estamos de las formas de tipo sacras (Ilamados o epifanías) o innatistas ("nací para ser maestra") que cierta bibliografía nacional e internacional mencionan a la hora de describir el uso del término que nos convoca (Hansen, 1994; French, 2006; Tenti Fanfani y Grimson, 2014; Tenti Fanfani, 2010).

Otro término que se repite en los discursos de elección vocacional es "probar". Muchas narrativas ponen de relieve al ingreso al profesorado como una prueba, casi como una exploración.

Y, cuando terminé con la secundaria, tenía 32 años, y no sabía si estudiar, qué estudiar, qué hacer. Me había gustado rendir las materias porque retomé los libros después de muchos años. Me di cuenta de que no era algo que me costara tanto, así que dije: "Bueno, vamos a probar" (Leandro, 39 años, residente).

Cuando tenía 18 entré al profesorado. Primero porque me quedaba cerca de mi casa y segundo porque nunca tuve problema para estudiar, siempre me fue fácil estudiar. Entonces dije "bueno voy a probar" y mi familia me dijo que vaya a estudiar algo y como no quería viajar mucho dije "bueno, me voy al profesorado que queda cerca" (Mariela, 32 años, residente). 
Revista de la Escuela de Ciencias de la Educación, año 14, nRo. 13, vol. 2, julio a diciembre de 2018. PÁginas 33-51. ISSN 1851-6297 (DESDE DICIEMBRE DE 2006 A DICIEMBRE DE 2017). ISSN 2362-3349 (EN LINEA). ¿ELEGIR POR VOCACIÓN O ELEGIR LA VOCACIÓN? EL DISCURSO VOCACIONAL EN ESTUDIANTES DE PROFESORADO Y DOCENTES NOVELES DE NIVEL PRIMARIO. Gustavo Mórtola y Maria Mercedes Lavalletto.

Los relatos expresan a individuos que visualizan a la docencia como una posibilidad que ha recortado entre otras al interior de un proceso de construcción profesional. Y que además deciden probar en el marco de discursos que también manifiestan elección. Es interesante la repetición fraseológica que se observa en varios individuos y que se estructura de la siguiente manera: "bueno" + "dije" (me) + "vamos" + "probar" (señaladas en negrita en los segmentos). Esta reiteración discursiva en el contexto de unos relatos de elección profesional manifiesta lo que se conocen como clichés o estereotipos lingüísticos. De esta manera se identifican a aquellas locuciones denominadas como frases hechas, modismos, dichos, refranes o muletillas que se aplican repetitivamente en situaciones determinadas (Ferrari, 1998).

La frase revela en el uso reflexivo del verbo "decir" un tipo de diálogo que mantienen consigo mismos estos individuos al momento de tomar decisiones sobre su futuro profesional. En el marco de discursos vocacionales de tipo laicos, el "me dije" da cuenta de un dialogo consigo mismo o lo que Shotter (1996) denomina proceso conversacional interior. Para este autor lo que piensa un individuo como discurso interior o soliloquio refleja las mismas características éticas, retóricas, políticas y poéticas que se expresan en las interacciones con otras personas en ámbitos públicos.

También la ingresante Magalí usa esta frase hecha como un recurso discursivo más que le permite describir su proceso de ingreso al profesorado. Se puede observar que lo hace sin ningún posicionamiento crítico o moral sobre su prueba.

Y es como que siempre tuve latente la idea de todo lo que tiene que ver con la educación y porque tengo bastante familia metida en el tema y así de experiencias de siempre contarme me interesaba, me gustaba y dije bueno voy a probar yo (Magalí, 18 años, ingresante).

Sin embargo, cuando son los otros u otras quienes prueban en el marco de otras razones o motivaciones que Magalí considera diferentes a las suyas propias, el probar adquiere otro peso moral aunque se aclare su respetabilidad.

Como de: bueno, quizás es fácil, es corto, es rápido, cosa que para mí es lo contrario. Es también respetable, es la decisión de otra persona. $Y$ hay que probar, después si no les gusta verán (Magalí, 18 años, ingresante).

Las narrativas de ingreso ponen de manifiesto lo que denominamos subjetividades probadoras. Un individuo que prueba es aquel que puede elegir ingresar a una carrera de nivel superior y salir de ella rápidamente si evalúa que no satisface sus expectativas. Nuevamente Magalí lo exterioriza claramente:

En realidad es en lo segundo en lo que me meto. Yo ingresé a principio de año en la Universidad de Buenos Aires al CBC de diseño gráfico y no me gustó, no me hallé (Magalí, ingresante, 18 años). 
Revista de la Escuela de Ciencias de la Educación, año 14, nRo. 13, vol. 2, julio a diciembre de 2018. Páginas 33-51. ISSN 1851-6297 (DESDE DICIEMBRE DE 2006 A DICIEMBRE DE 2017). ISSN 2362-3349 (EN LINEA). ¿ELEGIR POR VOCACIÓN O ELEGIR LA VOCACIÓN? EL DISCURSO VOCACIONAL EN ESTUDIANTES DE PROFESORADO Y DOCENTES NOVELES DE NIVEL PRIMARIO. Gustavo Mórtola y María Mercedes Lavalletto.

Utilizando terminología del campo de la economía y pensando en sujetos que actúan solo movilizados por la razón - cuestión a la que no adscriben los autores de este texto - parecería que el costo de oportunidad de este tipo de estudios es bajo para estos estudiantes de profesorado y docentes noveles. Los individuos que finalizan sus estudios secundarios pueden optar entre una oferta de carreras profesionales de nivel superior que es amplia y muy diversa en el enorme tejido urbano de la ciudad de Buenos Aires. Por otra parte, Argentina configuró un sistema de ingreso a sus universidades e institutos terciaros públicos de escasa selectividad formal en el acceso y que ofrece además la posibilidad de realizar los estudios sin el cobro de aranceles. En este contexto, "probar" estudiar una carrera de tipo profesional es una posibilidad que en el ámbito metropolitano tiene menores costos de oportunidad respecto de otros países en los que sus estudios de nivel superior están arancelados o cuentan con pruebas de selectividad (Rabossi, 2014).

\section{El enorme peso de la elección}

Focalicemos nuevamente nuestro análisis en el uso del término "elegir". Un vocablo que ya hemos visto que emerge con suma frecuencia en los discursos que expresan razones, motivaciones y causas del ingreso a los estudios de magisterio. Un tipo discursivo que expresa identidades electoras de una profesión y que, además, puede combinarse con imágenes de sí mismos como individuos probadores.

En un momento hasta dejo el profesorado por leer distintos autores, por cómo se llevó la clase. De llegar a la conclusión, bueno yo elegí educación porque es el cambio. Dejé Trabajo Social porque es asistencialismo y ahora que estoy en educación me estoy dando cuenta de que trabajo al servicio de unos pocos para reproducir desigualdades sociales (Patricia, 33 años, maestra novel).

Bueno, yo en particular elegí esto por un proyecto de transformación social. Yo creo que la educación es un acto político. Y todo pasa por la educación. Lo veo como un proyecto de transformación social. Por eso más que nada (Rocío, 33 años, maestra novel).

Por otra parte, la elección por la docencia puede sufrir cambios a lo largo del tiempo. En un momento de la vida se puede optar por el nivel inicial y en otra etapa por la primaria.

Por eso también la elección de primaria porque en el 2000 yo había ingresado en inicial, para ser profesora de Inicial. Y bueno, después cuando me di cuenta que no era lo mío dejé. Después en 2010 ingresé acá con el propósito de finalizar. Lo que me gustaba, la docencia pero cambiando de Inicial a Primaria (Adriana, 33 años, maestra novel). 
Revista de la Escuela de Ciencias de la Educación, año 14, nRo. 13, vol. 2, julio a diciembre de 2018. PÁginas 33-51. ISSN 1851-6297 (DESDE DICIEMBRE DE 2006 A DICIEMBRE DE 2017). ISSN 2362-3349 (EN LINEA). ¿ELEGIR POR VOCACIÓN O ELEGIR LA VOCACIÓN? EL DISCURSO VOCACIONAL EN ESTUDIANTES DE PROFESORADO Y DOCENTES NOVELES DE NIVEL PRIMARIO. Gustavo Mórtola y Maria Mercedes Lavalletto.

Si se ven a sí mismos eligiendo el trabajo de enseñar en el nivel primario, sus compañeros de profesorado también son electores.

Hay de todo, yo creo que hay de todo. Hay gente que elige por vocación, porque siempre quiso ser eso y hay otro más en mi situación. Querrán cambiar los trabajos o una salida laboral (Malena, 34 años, residente).

Ser un elector profesional conlleva la participación de un mundo de discursos e identidades en los cuales elegir "qué quiero ser" es algo cotidiano, natural o una cuestión común en la vida de una persona. Y que, además, está acompañada por la posibilidad de que allegados, amigos o parientes suelan opinar sobre las elecciones personales.

Pero bueno, le dije: "ustedes (nota: la madre y el padre) me eligieron la primaria, la secundaria, el jardín". Todo súper bien elegido pero esto es una decisión mía porque es para mí futuro y más que aconsejarme o decirme me gusta o no me podían obligar a nada (Magalí, 18 años, ingresante).

Mi mamá es maestra jardinera y mi papá es profesor de Educación Física. Entonces al principio les costó mucho entender que yo siga con lo mismo... era como una contradicción. Si bien la elección para ellos estaba buenísima, porque ellos la elegirían una y otra vez, también sabían que en lo económico a veces es un poco hostil, entonces, nada, como que no querían que nosotros pasemos por eso, digamos (Martina, 24 años, residente). Hay muchos que te dicen: "uy qué coraje querés ser maestra". Hay otros que te dicen: "es la mejor carrera que podías haber elegido. Yo sigo estudiando me sigo capacitando. Me encanta lo que hago" (Rocío, 33 años, maestra novel).

Le preguntamos al lector o lectora de este artículo: ¿Ud. eligió la profesión que desempeña? Elegir qué somos profesionalmente es algo que parece natural, algo que muchos hacemos en algún momento de nuestras vidas; generalmente en la juventud. Además, con seguridad en nuestra infancia o adolescencia hemos tenido que responder a algún familiar que nos interrogaba acerca de lo que queríamos ser cuando fuésemos grandes. O también hubo en nuestras vidas familiares o conocidos que tenían algo para decir sobre nuestras elecciones profesionales tal como narran nuestros entrevistados. Esa simple pregunta u opinión sobre las opciones que habíamos realizado nos ubicaba como electores que teníamos que escoger entre las diversas posibilidades que ofrece el mundo del trabajo para futuros desempeños laborales. Pero no todos los seres humanos portan este discurso que hace emerger identidades caracterizadas por la elección profesional.

Asimismo, estos intercambios discursivos dan cuenta de individuos que tienen que elegir la participación en un programa de transformación identitaria. Elegir qué ser profesionalmente pone de manifiesto a grandes masas de per- 
Revista de la Escuela de Ciencias de la Educación, año 14, nRo. 13, vol. 2, julio a diciembre de 2018. Páginas 33-51. ISSN 1851-6297 (DESDE DICIEMBRE DE 2006 A DICIEMBRE DE 2017). ISSN 2362-3349 (EN LINEA). ¿ELEGIR POR VOCACIÓN O ELEGIR LA VOCACIÓN? EL DISCURSO VOCACIONAL EN ESTUDIANTES DE PROFESORADO Y DOCENTES NOVELES DE NIVEL PRIMARIO. Gustavo Mórtola y María Mercedes Lavalletto.

sonas de nuestro tiempo que invierten tiempo y recursos para transformarse en otra cosa tras el paso por una institución formadora. Que alguien escoja estudiar magisterio expresa un proceso de transformación por el que se ingresa al profesorado con una identidad particular y se egresa con otra: Profesor de Enseñanza Primaria. "Soy maestro o maestra", frase que podría ser leída como algo simple y sencillo, muestra el complejo recorrido por un programa de socialización que cambia a las personas proveyéndolas de una identidad profesional. La formación inicial de profesionales conforma un programa social moderno que propone un currículum que a partir de la enseñanza de conocimientos, saberes, habilidades y disposiciones propias de un campo profesional forma a los individuos que en él se desempeñarán. Una majestuosa metamorfosis identitaria que parece poca cosa, una nadería; pero que sin embargo expresa una compleja transformación de los individuos participantes en instituciones, dispositivos y organizaciones sociales conformados a tal fin (1).

En la actualidad, enormes masas de individuos finalizan sus estudios secundarios lo que los coloca ante la posibilidad - hoy teñida con discursos de derechos - de continuar estudios de nivel superior para convertirse en profesionales de los más diversos campos laborales. Cabe señalar que nuestro tiempo presente ofrece una división del trabajo de una gran complejidad y multiplicidad en la que es posible optar por cientos de titulaciones habilitantes para el ejercicio profesional. Esto constituye una característica propia del proyecto de la modernidad que imbricó fuertemente a los sistemas educativos con el mundo del trabajo/empleo. La distribución de los individuos en los puestos del trabajo existentes tiene caminos diversos; sin embargo, en todos juega el sistema educativo consolidando trayectorias posibles. Algunas trayectorias educativas se articulan con campos laborales constituidos por profesiones de bajas cualificaciones. Otros mundos profesionales requieren de extensos, complejos y a veces onerosos recorridos - para los propios individuos y para el Estado - que permiten la obtención de un título.

El propio proceso vital que caracteriza en sus palabras el uso del término "elegir" es bastante reciente en su historicidad. ¿Podría una mujer de principios del siglo XX haber afirmado con tal potencia su decisión de estudiar magisterio con los tonos de libre electora autónoma tal como lo hacen estos estudiantes y docentes noveles? Consideramos que no. La socióloga marroquí Eva Illouz (2016) al analizar los fenómenos contemporáneos de conformación de parejas sexuales afirma que no pueden comprenderse sin incluir en el análisis los procesos de elección que configura la modernidad. Para esta investigadora;

La posibilidad de elección constituye el hito cultural que define la modernidad, al menos en el ámbito político y económico simboliza el ejercicio no solo de la libertad sino también de las dos facultades que justifican a esta última, es decir la autonomía y la racionalidad. En este sentido se trata de 
Revista de la Escuela de Ciencias de la Educación, año 14, nRo. 13, vol. 2, julio a diciembre de 2018. PÁginas 33-51. ISSN 1851-6297 (DESDE DICIEMBRE DE 2006 A DICIEMBRE DE 2017). ISSN 2362-3349 (EN LINEA). ¿ELEGIR POR VOCACIÓN O ELEGIR LA VOCACIÓN? EL DISCURSO VOCACIONAL EN ESTUDIANTES DE PROFESORADO Y DOCENTES NOVELES DE NIVEL PRIMARIO. Gustavo Mórtola y Maria Mercedes Lavalletto.

uno de los vectores más potentes en la configuración de la individualidad moderna: constituye a la vez un derecho y una competencia (p. 32).

Pero así como se elige una pareja también se opta por una profesión. Quizás la elección laboral no se haya extendido tanto como la de una pareja sexual, pero tal como ya afirmamos enormes cantidad de individuos contemporáneos eligen someterse a un programa de socialización que los transformará en profesionales titulados. En nuestro caso maestros y maestras de nivel primario. El mundo del trabajo y el empleo cuenta con dispositivos de socialización que conllevan discursos sociales específicos. La vocación es uno de ellos. Las narrativas vocacionales y de elección compartidas son el producto de dinámicas de individuación en tiempo presente. Tal como afirma Denis Merklen (2013) las políticas y dispositivos contemporáneos de producción de subjetividad se centran en la construcción de un individuo que se asuma como libre, activo y responsable de sí mismo. Merklen sostiene que uno de los dispositivos principales que han acentuado los fenómenos de individuación contemporánea es la división del trabajo.

La división del trabajo contemporáneo es uno de los dispositivos que han acentuado el deseo de libertad individual, una suerte de expresionismo, una búsqueda de autenticidad por parte de los individuos mismos, una voluntad estentórea de cultivar "una relación consigo mismo", una demanda social que toma también la forma de un deseo de autonomía en la determinación de la propia biografía, una voluntad "de ser sí mismo. (Merklen, 2013, p. 47).

Que multitudes contemporáneas elijan lo que quieren ser profesionalmente es una novedad en la historia humana que tiene menos de cien años. Más allá de esto, masas aún mayores de seres humanos del presente no tienen ninguna posibilidad de elegir lo que quieren ser. Trabajan de lo que pueden.

\section{La vocación en tiempos en que algunos pueden elegir la profesión}

Recapitulando el recorrido por este artículo se puede afirmar que ninguno de los entrevistados ha elegido ser docente de nivel primario por vocación. Bien vale la pena explicar con más detalle la afirmación de la primera oración de este apartado: los entrevistados no han elegido el trabajo de enseñar por vocación, han elegido su vocación.

Quizás, ante una encuesta que indagase sobre las motivaciones de ingreso al profesorado que tenga entre sus posibilidades de respuesta "por vocación" estos mismos entrevistados pondrían una cruz en esta opción. Pero nunca enunciaron tal cosa para sí mismos en las entrevistas realizadas en el marco de la presente investigación. Sí lo manifiestan en las elecciones de otros y otras tal como lo hemos observado en algunas de las narrativas compartidas. 
Revista de la Escuela de Ciencias de la Educación, año 14, nRo. 13, vol. 2, julio a diciembre de 2018. Páginas 33-51. ISSN 1851-6297 (DESDE DICIEMBRE DE 2006 A DICIEMBRE DE 2017). ISSN 2362-3349 (EN LINEA). ¿ELEGIR POR VOCACIÓN O ELEGIR LA VOCACIÓN? EL DISCURSO VOCACIONAL EN ESTUDIANTES DE PROFESORADO Y DOCENTES NOVELES DE NIVEL PRIMARIO. Gustavo Mórtola y María Mercedes Lavalletto.

En las entrevistas se observa una fuerte imbricación entre vocación y elección. Así el término vocación coagula al proceso social de articulación y circulación entre los individuos y la fragmentada división del trabajo contemporáneo. Particularmente con aquellas esferas laborales que se han profesionalizado y que exigen para su desempeño largas formaciones especializadas y títulos habilitantes. Sostenemos que "elegir la vocación" no es igual a "elegir por vocación". En el primer caso vocación se asocia a una decisión individual de optar entre las múltiples ofertas de formación profesional disponibles en la actualidad. Más en una megalópolis como es Buenos Aires. Conseguir una titulación de nivel secundario autoriza a cientos de miles de individuos a aspirar a convertirse en algo que apenas terminado el nivel medio aún no son: profesionales titulados. No está de más recordar que no todos los habitantes del territorio nacional podrán serlo. Ser un profesional titulado expresa complejos procesos de selección social y a masas de individuos que participan de ellos. El discurso de elección vocacional pone de manifiesto que en nuestro tiempo presente se elige ser parte de programas institucionales de socialización que forman y titulan profesionales.

¿Qué es un programa institucional? Para Dubet (2006) es un tipo particular de socialización, una forma específica de trabajo sobre los otros que transforma valores y principios en acción y en subjetividad por el sesgo de un trabajo profesional específico y profesionalizado. El programa socializa al individuo y pretende convertirlo en sujeto, le inculca un habitus y una identidad conforme a los requisitos de la vida social. El programa institucional "produce un individuo autónomo, es decir, un actor conforme a las normas, a las reglas sociales" (Dubet, 2006, p. 44). Un trabajo sobre los otros que al mismo tiempo que brinda autonomía, produce heteronomía. Los institutos de profesorado forman docentes con identidades, saberes y disposiciones particulares habilitados por el Estado para ocupar ciertos puestos laborales en la particular división del trabajo de un territorio específico.

Los individuos que eligen este proceso de transformación de sí mismos - por supuesto, sin conciencia de que participan de tal fenómeno complejo cuentan con un discurso posible para sostener su ingreso al profesorado tanto para sí como para otros cuando deben hacer públicas su opción profesional. Así, "elegir la vocación" liga una variedad de tipos discursivos que representan prácticas, trayectorias y anhelos en juegos del lenguaje vinculados con fenómenos de selección, formación profesional y distribución de individuos en una esfera específica de la división del trabajo contemporáneo: el cuerpo de docentes de nivel primario. Sin tener estudios comparativos que lo sustenten nos animamos a afirmar que "eligen la vocación" abogados, arquitectos, médicos, enfermeros, policías, entre otros campos laborales que se han profesionalizado (2). ¿Cuánto de electora tiene una mujer que limpia baños ajenos para ganarse el pan de cada día? Como se sostiene en el título de este 
Revista de la Escuela de Ciencias de la Educación, año 14, nRo. 13, vol. 2, julio a diciembre de 2018. PÁginas 33-51. ISSN 1851-6297 (DESDE DICIEMBRE DE 2006 A DICIEMBRE DE 2017). ISSN 2362-3349 (EN LINEA). ¿ELEGIR POR VOCACIÓN O ELEGIR LA VOCACIÓN? EL DISCURSO VOCACIONAL EN ESTUDIANTES DE PROFESORADO Y DOCENTES NOVELES DE NIVEL PRIMARIO. Gustavo Mórtola y Maria Mercedes Lavalletto.

apartado vivimos en tiempos que algunos eligen la vocación en tanto enormes mayorías no pueden hacerlo. Bauman (1998, p. 60) manifestaba en un trabajo previo a todos sus "líquidos" que la vocación es el privilegio de las elites. Una afirmación desafiante del sociólogo polaco pero que abre puertas para pensar el mundo del trabajo y el empleo, su enorme fragmentación y las posiciones sociales diferenciales que se asocian a los distintos tipos de profesiones.

Las causas, motivos y razones que explican la elección profesional son múltiples y diversas. Ninguno de los entrevistados menciona una única motivación como explicación de su ingreso al profesorado y suelen combinarlas con tonalidades propias. Sin embargo, que un relato de elección y sus causas tenga tonos personales no implica una multiplicidad infinita de discursos individuales. Hay más similitudes que divergencias en las narrativas de elección vocacional. Venir de una familia de docentes, el gusto por los niños, la transformación de la sociedad, por mencionar algunas de las que sostienen los relatos enunciados en las entrevistas, están bajo el paraguas de "elegir la vocación". En esas similitudes se observa un discurso que excede la conciencia de cada uno de los entrevistados, hay un discurso social que tiene potencia hegemónica para articular un tipo de habla asociada a una esfera específica del mundo del trabajo y el empleo. El discurso de elección de los docentes tiene tópicos que lo caracterizan en tanto es específico para un tipo de trabajo en particular. Una esfera profesional que tiene su historia, sus normativas, su organización, sus tecnologías y una discursividad hegemónica con toda la contingencia que esto conlleva. La vocación no es igual hoy que ayer.

Estamos en presencia de individuos que se perciben como autónomos, con capacidad de libre elección, con posibilidad de construir un futuro profesional para sí mismos enseñando en el nivel primario. Hay una vasta bibliografía que describe los fenómenos contemporáneos de individuación como el surgimiento de un yo con alta capacidad de expresión, "liberado" de constricciones y cadenas institucionales, valorativas, dogmáticas. En esta liberación del yo y su potencia expresiva existe también una amplia bibliografía que lo vincula con la división del trabajo de nuestra época, el debilitamiento de las identidades profesionales, las innovaciones tecnológicas, los procesos de desregulación del mundo del empleo, la responsabilización del individuo en la construcción de su trayectoria profesional, entre otras características (Bauman, 1998; Castel, 2002; Dubet, 2006 y 2013; Sennet, 2000).

Sin embargo, ante la percepción de autonomía electoral no podemos dejar de recordar que este tipo de discurso es enunciado por mujeres. La elección vocacional de la enseñanza primaria es una opción que continúa siendo eminentemente femenina desde la conformación del trabajo de enseñar como empleo de Estado en el siglo XIX (Birgin, 1999; Lionetti, 2007). De tal manera la división del trabajo adquiere otro ingrediente en el campo del trabajo de enseñar en el nivel primario: su carácter generalizado. Somos concientes de que 
Revista de la Escuela de Ciencias de la Educación, año 14, nRo. 13, vol. 2, julio a diciembre de 2018. Páginas 33-51. ISSN 1851-6297 (DESDE DICIEMBRE DE 2006 A DICIEMBRE DE 2017). ISSN 2362-3349 (EN LINEA). ¿ELEGIR POR VOCACIÓN O ELEGIR LA VOCACIÓN? EL DISCURSO VOCACIONAL EN ESTUDIANTES DE PROFESORADO Y DOCENTES NOVELES DE NIVEL PRIMARIO. Gustavo Mórtola y María Mercedes Lavalletto.

profundizar en este tópico requiere de otros marcos conceptuales y analíticos que con seguridad permitirían dilucidar con mayor relevancia los aspectos en que el género interviene en el discurso de elección vocacional.

Volvamos a la cuestión de que no hemos encontrado discursos que enuncien una elección realizada "por vocación". No aparecieron epifanías, llamados o innatismos del tipo "nací para ser maestra". Las narrativas de elección son de tipo secular, laicas, que expresan yoes que se perciben autónomos y con una importante reflexión sobre los motivos, causas y razones por las que han decidido ser maestros. En algunos casos hasta expresan núcleos de sentidos instrumentales en tanto aspiran a mejores y más seguros empleos de los que han obtenido en sus trayectorias laborales. En las narrativas son los otros y otras quienes pueden elegir "por vocación", cuestión que aparece desvalorizada frente a unas razones personales que parecen tener mayor valía. Pero ni ellos mismos ni sus compañeros de estudios o los colegas de las escuelas en las que trabajan han dejado de elegir.

Los discursos de elección vocacional dan cuenta de individuos que han pensado -y mucho- sobre un tipo de decisión que es de suma importancia por la trascendencia que tiene en una vida. Han dialogado consigo mismos en torno a su voluntad de ser maestras y maestros y en muchos casos se observa que han tenido que hacer públicas las razones, motivos y causas de su elección. Este tipo de discurso tiene grandes posibilidades de enunciarse en ámbitos públicos y participar de los debates en torno a la profesión de enseñar. Parientes, amigos y colegas parecen tener algo para decir sobre las elecciones profesionales personales. Y, también, sobre el trabajo de enseñar. Así, el discurso vocacional docente expresa hegemonías contingentes que se juegan en lo decible y lo indecible, lo pensable y lo impensable, lo sentible y lo que es imposible de sentir respecto de la elección del magisterio. Una hegemonía que es en tiempo presente y en continua disputa de sentidos.

\section{Notas bibliográficas}

1. A partir del clásico libro "Schoolteacher" (1975) del sociólogo norteamericano Dan Lortie se ha analizado el proceso de socialización de los docentes y se ha comprobado que el dispositivo excede a la formación de grado. Lortie puso en evidencia como la escolarización previa a los estudios profesorales y la socialización laboral son núcleos tan o más relevantes que la propia formación de grado en la formación de la docencia.

2. Para el caso de la policía y su vocación se puede consultar el trabajo "Cómo se construye un policía. La Federal desde adentro" (2016) cuya autora es Mariana Galvani

\section{Referencias bibliográficas}

- Abramowski, A. (2010). Maneras de querer. Los afectos docentes en las relaciones pedagógicas. Buenos Aires, Argentina: Editorial Paidós. Cuestiones de Educación.

- Alliaud, A. (1993). Los maestros y su historia: los orígenes del magisterio argentino. 
Revista de la Escuela de Ciencias de la Educación, año 14, nRo. 13, vol. 2, julio a diciembre de 2018. PÁginas 33-51. ISSN 1851-6297 (DESDE DICIEMBRE DE 2006 A DICIEMBRE DE 2017). ISSN 2362-3349 (EN LINEA). ¿ELEGIR POR VOCACIÓN O ELEGIR LA VOCACIÓN? EL DISCURSO VOCACIONAL EN ESTUDIANTES DE PROFESORADO Y DOCENTES NOVELES DE NIVEL PRIMARIO. Gustavo Mórtola y Maria Mercedes Lavalletto.

Buenos Aires: Centro Editor de América Latina

- Alliaud, A. y Antelo, E. (2009). Los gajes del oficio. Enseñanza, pedagogía y formación. Buenos Aires: Aique.

- Angenot, M. (2010). El discurso social. Buenos Aires, Argentina: Siglo XXI Editores.

- Bauman, Z. (1999). Trabajo, consumismo y nuevos pobres. Barcelona, España: Ed. Gedisa.

- Birgin, A. y Pineau, P. (2006). Esos raros peinados nuevos. ¿Qué traen los nuevos docentes? En Feldfeber, M. y Andrade Oliveira, D. (Comps.). Políticas educativas y trabajo docente (pp. 161-181). Buenos Aires, Argentina: Ediciones Novedades Educativas.

- Birgin, A. (1999). El trabajo de enseñar. Buenos Aires, Argentina: Troquel.

- Castel, R. (2002). La metamorfosis de la cuestión social. Buenos Aires. Argentina: Paidós.

- Davini, M.C. y Alliaud, A. (1995). Los maestros del Siglo XXI. BuenosAires, Argentina: Miño y Dávila Editores.

- Dubet, F. (2013). El trabajo de las sociedades. Buenos Aires: Amorrortu Editores.

- Dubet, F. (2006). El declive de la institución. Profesiones, sujetos e individuos en la modernidad. Barcelona: Gedisa.

- Estola, E. (2003). In the Language of the Mother. Re-storying the Relational Moral in Teacher's Stories.Ponenciapresentadaen: Faculty of Education, University of Oulu. Linnanmaa, Finlandia. Recuperado de http://jultika.oulu.fi/files/isbn9514269713.pdf

- French, J. (2006). Life Calling and Vocation: an Exploratory Qualitative Analytical Examination among University Students. Thesis of Degree of Master of Arts.Trinity Western University.Langley, Canadá.Recuperado de http://www2.twu.ca/cpsy/theses/ frenchjared.pdf

- Ferrari, A, (1998). Estereotipos lingüísticos y traducción. Revista Hyeronimus. Vol. 6-7., pp. 25-34. Recuperado de http://cvc.cervantes.es/lengua/hieronymus/ pdf/06_07/06_07_025.pdf

- Gottfredson, L. (2002). Gottfredson's Theory of Circumscription, Compromise, and Self-Creation. En D. Brown (Ed.).Career choice and development (pp 85-148).San Francisco, EEUU: Jossey Bass.

- Hansen, D. (1994). Revitalizing the idea of Vocation in Teaching.Philosophy of Education Society Yearbook, Vol. 50, 1. pp. 411-419. Recuperado de http://tnmonaghan.files. wordpress.com/2010/04/hansen-d-revitalizing-the-idea-of-vocation-in-teaching.pdf

- Illouz, E. (2016). ¿Por qué duele el amor? Una explicación sociológica. Buenos Aires, Argentina: Capital Intelectual

- Lionetti, L. (2007). La misión política de la escuela pública: formar a los ciudadanos de la república (1870-1916). Buenos Aires, Argentina: Miño y Dávila.

- Lortie, D. (1975). School teacher. Chicago, EEUU: University of Chicago Press.

- Measor, L. (1985). Critical incidents in the classroom: identities, choices and careers. En S. Ball y I. Goodson (Eds.), Teachers, lives and careers (pp. 61-77), Lewes, ReinoUnido:Falmer Press.

- Merklen, D. (2013). Las dinámicas contemporáneas de la individuación. En R. Castel, G. Kessler, D. Merklen y N. Murard, (Comps.) Individuación, precariedad, inseguridad. 
Revista de la Escuela de Ciencias de la Educación, año 14, nRo. 13, vol. 2, julio a diciembre de 2018. Páginas 33-51. ISSN 1851-6297 (DESDE DICIEMBRE DE 2006 A DICIEMBRE DE 2017). ISSN 2362-3349 (EN LINEA). ¿ELEGIR POR VOCACIÓN O ELEGIR LA VOCACIÓN? EL DISCURSO VOCACIONAL EN ESTUDIANTES DE PROFESORADO Y DOCENTES NOVELES DE NIVEL PRIMARIO. Gustavo Mórtola y María Mercedes Lavalletto.

¿Desinstitucionalización del presente? (pp. 45-86) Buenos Aires, Argentina: Paidós.

- Mórtola, G. y Lavalleto, M., (2016). El discurso vocacional de los ingresantes al profesorado de educación primaria. En Feldfeber, M., Saforcada, F., Duhalde, M. y Birgin, A. (Comps).Formación y trabajo docente: aportes para la democratización educativa (pp. 168-183). La Plata, Argentina: FaCHE-UNLP.

- Tenti Fanfani, E. y Grimson, A. (2014). Mitomanías de la educación argentina. Buenos Aires, Argentina: Siglo XXI Editores.

- Tenti Fanfani, E. (2010). Estudiantes y profesores de la formación docente: opiniones, valoraciones y expectativas. BuenosAires: Ministerio de Educación de la Nación.

- Rabossi, M. (2014). Acceso (¿Ingreso?) a las universidades nacionales argentinas: permisividad y consecuencias. Revista de Educación. Vol. $7 N^{\circ} 2$. Recuperado de http:// www.scielo.edu.uy/scielo.php?script=sci_arttext\&pid=S1688-74682014000200005

- Rascovan, S. (2004). Lo vocacional: una revisión crítica. Revista Brasileira de OrientaçãoProfissional, 5 (2), pp. 1-10. Recuperado de http://pepsic.bvsalud.org/pdf/ rbop/v5n2/v5n2a02.pdf

- Sennett, R. (2000). La corrosión del carácter. Barcelona, España: Anagrama.

- Shotter, J. (1996). El lenguaje y la construcción del sí mismo. En Pakman, M. (Comp.) Construcciones de la experiencia humana (pp. 213-227). Barcelona, España: Ed. Gedisa.

- Verd, J. (2006). La construcción de indicadores biográficos mediante el análisis reticular del discurso. Una aproximación al análisis narrativo-biográfico. REDESRevista hispana para el análisis de redes sociales. Vol.10, 7. Recuperado de http:// revista-redes.rediris.es/html-vol10/vol10_7.htm

- Weber, M. (1997). El político y el científico. México: Fondo de Cultura Económica. 